\title{
A Research for Literariness of Translation-With an Example of English Version Medicine
}

\author{
Qing Yang \\ Sichuan Agricultural University, China
}

\begin{abstract}
Traditionally, people always focus on the faithfulness and equivalence of translation as well as the extrinsic approach to literature study, which results in the ignorance of translation's literariness. However, this paper values nature and artistic value of translation in intrinsic way to draw people's attention to literariness and it is going to analyze literariness in translation, with an example of English version Medicine written by Lu Xun and translated by Yang Hsien-yi and Gladys Yang, by anglicizing the new imagery caused by changes of characters' nomination within the new context via the comparative analysis of words selection, rhetoric and cultural differences between source text and translation.
\end{abstract}

Index Terms - intrinsic approach, translation, literariness, Medicine

\section{INTRODUCTION}

\section{A. Rationale}

Translation activities play a vital role in today's communication among cultures and countries, and they become far more important for the sake of literary spread. Since translation is the final and direct one for foreign people to acknowledge one country's literature, people judge or criticize it. Many learners has put forward relevant theories, such as dynamic equivalence or functional equivalence, discourse and translator, text type as well as pragmatic of translation (Fei, 2003). Obviously, these theories focus on the faithfulness of translation. Meanwhile, a few learners discuss its acceptability and they think "Only translation is accepted by readers can it be successful..." (Zeng \& Zhong, 2005, p.142). And in accordance with data from CNKI, there is only one paper specializing in values of translation's literariness among doctoral dissertations and none in core journals from 1994 to $2012^{1}$. It is evident that literature's literariness is being belittled at present as people always evaluate translation from corresponding principles or acceptability in cultural transmission which emphasize the relation between literature and society, politics or history. Liu Xiangyu once pointed out: “...theorists and critics [in China] ...hold an extrinsic approach to literature study...study of literary nature is neglected [if relation between literature and reality or history is over emphasized] resulting in the loss of literature's literariness and art's artistry" (Wellek, 2010, p. 8). Moreover, influenced by traditional literary concept such as writings conveying truth, learners usually view works with tremendous effects as literature, causing the overlook of literature's nature and the real one invisible. Therefore, Guo Shaoyu thinks highly of pure literature and says: "The problems of literary criticism in China are discussing either 'writings conveying truth' or theology..." (Yan, 2010, p.101) In fact, after one literature work being translated, it will become new literature and get diversified aesthetic constitution due to the unavoidable variation in literature, and readers may receive different aesthetic effects like "plain", "graceful" or "delicate", etc. It goes without saying that studying one translation in extrinsic way is of great importance, but the more is less, which means literature nature can be covered and literature will descend into "product" with certain functions. For this reason, this paper focuses on nature and aesthetic internal factors of literature so as to analyze the literariness of translation, which attributes to a better look at it and better appreciation as well as avoid it reducing into a role with pure political, economic, social and educational function. And the underlying communication among cultures may be promoted in this way.

\section{B. Objective and Methodology}

This paper stresses on studying literary works in intrinsic way and the internal factors caused aesthetic experiences. Noticeably, literary works in this paper are not the ones that created by writer directly but the translation after translation activities. It is well-known that Lu Xun's novels are in a simple and plain style, involving sobering language as well as gloomy and black humor consisting of deep thoughts and contents. And vivid social presence from the revolution of 1911 to May fourth movement is displayed in his novels while feudalism or feudal ethical code is attacked by shaping character's image. Among them, Medicine represents Lu Xun's tragic fiction containing deep meanings through situation setting in a gloomy style $(\mathrm{Ji}, 2010)$. Meanwhile, his novels achieve great influence in world literature, for instance, "the English versions Blessing and Medicine have been selected as the textbook of Chinese literature of East Asian languages and literature at Yale University" (Wang \& Wei, 2010, p.105). And many translators are working

\footnotetext{
${ }^{1}$ The data is from CNKI: http://202.115.182.57/kns50/ (accessed 10/6/2013).
} 
on his novels like George A. Kennedy, American journalist Edgar Snow, Yang Hsien-yi and Gladys Yang and British scholar Julia Lovell and so on. But in China, those who study English version of Lu Xun's novels mostly choose the ones translated by Yang Hsien-yi and Gladys Yang and Lyle (Ma, 2011). And this paper uses Yang Hsien-yi and Gladys Yang's version, because "[they] insist in the translation thought of introducing Chinese culture faithfully" (qtd. in Dang, 2012, p.72), which make their translation unaffected and maintain lots of original narrative structures, culture and national characteristics. So their translation, with high quality and value, provides good channels for foreigners to know Chinese literature and culture.

However, some learners have analyzed "the gains and losses as well as the advantages and disadvantages of Medicine's English versions from Julia Lovell and Yang Hsien-yi and Gladys Yang” (Hou \& Peng, 2011, p.31). At the same time, others have analyzed "the achievements that [they] have gotten on realizing the situation of source text." (Meng, 2003, p. 36) and pointed out shortcomings based on dialect translation. Clearly, they try to evaluate pros and cons of translation in various ways. It is true that criticisms of translation's quality are of great significance and mistranslation must be avoided. But if too much attention has been drawn on whether the narrative structure, expression form and skill of translation equal to source text and one translation can affect world greatly or not, the innate features of literature itself may be less focused. Hence this paper studies Medicine's English version in an objective attitude instead of commenting its good and bad. And this paper values nature and artistic value of translation in intrinsic way to draw people's attention to literariness and it is going to analyze literariness in translation by anglicizing the new imagery caused by changes of characters' nomination within the new context via the comparative analysis of words selection, rhetoric and cultural differences between source text and translation.

\section{THE LITERARINESS OF TRANSLATION TEXT}

\section{A. Traditional Viewpoints on Translation And Translation Text}

According to data, for traditional translation study, “...translation solely means that transforming from one language to the other. So translators' only choice is to make their works faithful... and express it fluently in target text" (Wang, 2009, p.19). As a result, various translation principles come to existence and excellent translation must cater to these principles. For example, George Campbell once stated "three principles for good translation" (Dang, 2012, p. 30). Nevertheless, some learners consider that translation should be studied in comparative literature and say: "Translation in comparative literature is a literary study with no limitation to understanding or expression of linguistic phenomenon and no evaluation of its good or bad..." (Chen, Sun \& Xie, 1997, p. 142) And Professor Xie Tianzheng thinks that the study of mediotranslatology "has outstripped traditional words and phrases translation. What it emphasizes is not traditional 'faithfulness', 'expressiveness' and 'elegance' but 'creative treason"” (Cao, 2001, p. 4). Additionally, André Lefevere, the famous comparative literature scholar, studies translation via the angle of comparative literature and believes that "Every translation is the revision of source text" (Wang, 2009, p. 21). So, translation is more than the transformation between two languages but becomes a literature consisting of characteristics of literary study and creativity in comparative literature.

Unfortunately, the definition of translation has no been known and the proper position has not been taken shape currently. To the contrary, translation is considered as "the 'reproduction' of source text...or the similar concept such as 'imitation' or 'copy"' (Xu, 2002, p. 16). Such view stems from Aristotle, who thinks that "art imitates nature...every art in various styles is the production of imitation" (Zhu, 2008, p. 22). In the meantime, quite a few people think translation is subordinate and say: "Source text ranks first while translation second; source text is certified product while translation substandard goods" (Xu, 2002, p. 17). While Professor Xu Jun (2002), deems that "...although source text and translation are cognate... [They] do not imitate directly... which implies that translation has creative values." (p.20) In the West, Walter Benjamin utters in The Task of the Translator: "Translation is a sign of work's continuation which is its afterlife" (Teng, 2006, p. 133). This concept coincides with some learners in China. Distinctly, the identity of translation has not reached a common sense, but the emphasis on the values of translation has being the focus amid academia. From data along with relevant research on translation, the author thinks translation is a special literary work experiencing translation activities and readers' acceptation, which has new aesthetic structure, aesthetic factor and literariness. But due to the differences of language cognition, cultural connotation, history and national psychological characteristics, translation comes from source text but differs from it; it becomes the work in foreign language but differs from these works created in foreign language.

\section{B. Translation as Literature}

For literary study, there are two perspectives ${ }^{2}$, namely, the extrinsic approach and the intrinsic approach to literature study. In accordance with Wellek (2010), the intrinsic study to literature focuses on the internal factors that cause aesthetic experience and literariness referring to "...essential features of literature, which is a term, put forward by

\footnotetext{
${ }^{2}$ According to Literature Theory written by Wellek, the extrinsic approach to literature study focuses on research of writers, literature sociology and psychology in literature; while the intrinsic approach to literature study focuses on existing form of literary works, the nature of narrative works, stylistics, rhythm, image, metaphor, symbol, etc, which relate to literature itself.
} 
Roman Jakpobson (1891-1982) in 1920s..." (Zhou, 2003, p. 51) Thereby the nature of literature should be stressed including literature works' language, structure, form and skill. Simultaneously, Professor Cao Shunqing (2001) states that "Literariness is the crucial question of aesthetic which is inherent regularity of the existence of literary and art works" (p.44). Although the important channel of communications among cultures mainly depends on turning source text to translation by languages, "cultural filtering will happen in the procedure of translation" (Cao, 2001, p.103) because of aesthetic, psychology and cultural factors mixed in translation process. And based on his views, "cultural filtering" leads to "variations of literature" which is inevitable. Similarly, if translation is studied in variations studies in comparative literature, the focus is not on the transformation of linguistic phenomenon but on the aesthetic characteristic of translation brought by variation.

Moreover, receiver of literariness is reader. After reading one literature work, reader will receive aesthetic experience from the aesthetic constituents ${ }^{3}$ of work instead of external elements. From Liu Miqing's (2005) viewpoints, such factors form internal factors of one work's disposition. And in Medicine, there are lots of methods of rhetoric such as metaphor, symbol, comparison or irony, and whatever it is nomination or environmental description, it contains implication. Furthermore, Hans Robert Jauss and Wolfgang Iser, who stand for the aesthetic reception theory, have talked about "indeterminacy", which means "the deletion of correspondence between phenomena described in text and objects in real world" (qtd. in Zhou, 2012, p. 83); they have also talked about "blanks" referring to "vacancy of the connection of each semantic unit along with the psychological blanks caused by deny over the sight to which readers used" (Zhou, 2012, p.83). And for translation, "blanks" exists here requiring readers to overfly "blanks" to stir up imagination or thinking and receive aesthetic perception in the end. But some writers prefer to give certain special meanings to characters' nomination causing implications in characters' names, which conveys intentions and thoughts of works. Looking at Lu Xun's novels, one can notice that the art of nomination is unique, which connects intentions with characters' status, personality and fate by peculiar nomination so as to shape characters' image and deliver thoughts. Yet owing to variation in literature, after translation activities, the implication in nomination will be filtered ending with incomplete representation which presents new nomination and new imagery. While in new context, new imagery conflicts with context resulting in the production of "blanks" providing one of new aesthetic traits. That's why the analysis in this paper is from clues of nomination.

\section{The Hypothesis of Literariness}

When it comes to translation, the first thing strikes people is faithfulness, which is regarded as "the leading theory in linguistic school of translation" (Wang, 2005, p. 79), valuing the quality of one translation. Meanwhile, Professor Zhao Yanchun has stated and emphasized that "converge, meaning that the source text and translation should equal as much as possible, is the second translation principle."(qtd. in Cong, 2006, p. 77). Obviously, faithfulness becomes the vital standard to value translation.

On the other hand, people always adopt extrinsic approach to study literature, dating back to the theory of imitation and representation from Plato and Aristotle thousands of years ago, which emphasizes the relation between literature and society, history or era, etc (Wellek, 2010). As a result, they discuss literal extrinsic problems ending in less attention to the nature of literature.

It is disputable that translators must follow some translation principles to avoid some errors such as mistranslation; and it is of great significance to study literature in extrinsic way. However, the literariness of translation, the innate property of literature, will be ignored if people always focus on how much translation can realize the source text plus over-focus on extrinsic problems of translation. Therefore, the literariness and artistic value of translation will get attached much more if people pay much attention to cultural translation, stressing on the culture behind text, and intrinsic approach to literature study with more focus on the nature of literature when studying literature,

\section{ANALySIS ON THE Literariness OF THE TRANSLATION OF MEDICINE}

The excerpts in this paper are based on clues of nomination (Lu, 2009). According to previous statements in this paper, in Lu Xun's novels, characters' names are unique, which contain particular symbols involving connections among characters' social experiences, characteristics and themes. Take the example of Medicine, different rhetoric of nomination can be found. The symbol in rhetoric is used, for instance, “'Zhong Guo' used to be called 'hua xia'. And in Medicine, "hua" and "xia" are used as two surnames of two families which imply the whole China's tragedy through their tragic fate." (Cui, 2009, p.118); while the comparison is also used in source text: "Xia Yu is a revolutionist but Hua Laoshuan is a peasant. The euphony of 'yu' in Chinese is 'jade' implying the praise of revolutionist; while the euphony of 'shuan' is 'tide' meaning the unconsciousness..." (Xu, 2003, p. 11) In addition to these rhetorical devices, there are other ones such as comparison. Undoubtedly, translation activities cannot be completely accurate and perfect, just as Professor Cao Shunqing (2006) has said that "the theory of translation is talking about...that translation is not completely accurate which causes creativity of translation and new value of translated literature." (p.15)In other words,

\footnotetext{
${ }^{3}$ From Liu Miqing's viewpoints that Constituent consists two types: preventative component, also known as the beauty of language form and formal beauty of substance's existence in aesthetic, is visual; while non-preventative component, also known as non-quota factors, includes artistic conception, verve, momentum, modality and feature which are the internal factors of one work's disposition.
} 
after translation activities, source text turns into translation and creates new characters' image, imagery and values because of variation. Here some of the changes of nomination in Medicine have been presented just as following: Hua Laoshuan is translated to Old Shuan, Xiao Shuan is translated to Little Shuan and Xia Yu is replaced by Son.

It cannot be denied that there are so many differences of nomination between two languages. Hardly can one find corresponding names between two languages, let alone such equivalent meanings and implications behind names. In the English version of Medicine, special implications in names have been filtered resulting in the appearance of characters' new image which leads to new imagery in translation. So in this paper, the changes of Hua Laoshuan's image, the main character whose name is a typical nomination with implication in Chinese, will be anglicized only owing to space constraints.

\section{A. Analysis on Words Selection}

Source text: Lao Shuan reached his pocket for silver dollars hurriedly, and quiveringly handed to this man. Nevertheless, he didn't dare to catch his goods. ${ }^{4}$

The version: Hurriedly Old Shuan fumbled for his dollars, and trembling he was about to hand them over, but he dared not take the object.

In the source text, the name "Hua Laoshuan" means restriction of thoughts and callousness, while in translation the name becomes "Old Shuan". From the excerpt, especially these words such as "hurriedly", "fumble", "tremble", "dare", it can be noticed that "Hua Laoshuan" becomes a coward and lowly person with no trace of restriction of thoughts. More specifically, the meaning of "tremble", from Oxford Advanced Learner's English-Chinese Dictionary (7th ed.), is: to shake in a way that you cannot control, especially because you are very nervous, excited, frightened, etc; to be very worried or frightened. Thus just this word has shaped new image of "Hua Laoshuan".

Source text: He sent his huge hand towards Hua Laoshuan, while the other pinched one fresh red steamed bread as the fresh red drops were dripping to the ground. ${ }^{5}$

The version: This man was thrusting one huge extended hand towards him, while in the other he held a roll of steamed bread, from which crimson drops were dripping to the ground.

The key phrase - "steamed bread with human blood" comes to the scene in the underline sentence for the first time in Medicine. In the source text, Lu Xun does not point out that steamed bread is covered human blood, namely, the blood of Xia Yu. And in translation, the phrase of "red drops" is translated to "crimson drops" without any addition. Based on the explanation of "crimson" in Oxford Advanced Learner's English-Chinese Dictionary (7th ed.), it means: dark red in color, which evokes readers' imaginations and thinking: what are the dark red drops? Why he went to buy steamed bread? What is implication behind such description? Of course, if in the source text, readers can grasp the meaning by implications of nomination in the context, but the new name does not carry any implication. The translation presents no obvious answer. Readers must contemplate by themselves through "blanks" or "indeterminacy" caused by conflicts between character's new image and imagery in the new context. Hence, aesthetic senses merge in readers' mind.

\section{B. Analysis on Rhetoric}

Source text: "Hey! The money, the goods!" said a man entirely in black who stood before Hua Laoshuan. His eyes, as sharp as daggers, made Laoshuan shrink to half of normal size. ${ }^{6}$

The version: "Hey! Give me the cash, and I'll give you the goods!"A man clad entirely in black stood before him, his eyes like daggers, making Old Shuan shrink to half his normal size.

In translation, the hyperbole is used in the underline sentence, especially the word "shrink". And according to the explanation from Oxford Advanced Learner's English-Chinese Dictionary (7th ed.), "shrink" means: to become or to make something smaller in size or amount; to move back or away from something because you are frightened or shocked. Hua Laoshuan's weak and coward image has been built vividly by this word. In reality, translator can choose other words that can demonstrate character's tragic fate clearly but he does not. And in this way, translation shows readers the implication appropriately and leaves them tremendous imaginations.

Source text: One of them turned back to look at him, though he couldn't see his appearance distinctly, his eyes shone with a gleam of plunder which seems like very famished people's catching sight of food. ${ }^{7}$

The version: One of them even turned back at him, and although he could not see him clearly, the man's eyes shone with a lustful light, like a famished person's at the sight of food.

\footnotetext{
${ }^{4}$ This excerpt is translated by author. The Chinese one is: “老栓慌忙摸出洋钱, 抖抖的想交给他, 却又不敢去接他的东西。”

${ }^{5}$ This excerpt is translated by author. The Chinese one is: “那人一只大手, 向他摊着; 一只手却撮着一个鲜红的馒头, 那红的还是一点一点的 往下滴。”

${ }^{6}$ This excerpt is translated by author. The Chinese one is: “喂! 一手交钱, 一手交货! 一一个浑身黑色的人, 站在老栓面前, 眼光正像两把 刀, 刺得老栓缩小了一半。”

${ }^{7}$ This excerpt is translated by author. The Chinese one is: “一个还回头看他, 样子不甚分明, 但很像久饯的人见了食物一般, 眼里闪出一种㩲 取的光。”
} 
Seemingly the simile is used in the underline sentence; actually, it is understatement that exposes these people's greedy and aggressive expression hinting at Chinese people in the beginning of the 20th century in China. But in translation, the translator does not present the implication but remain the original expression of the context which causes "blanks" and readers may wonder: why the author plans such strange situation?

\section{Comparative Analysis on Cultural Meanings}

Source text: Suddenly, Hua Laoshuan sat up in bed, struck a match and lit the grease-covered oil lamp which made the two rooms in the teahouse filled with bluish-white light. ${ }^{8}$

The version: Old Shuan suddenly sat up in bed. He stuck a match and lit the grease-covered lamp, which shed ghostly light over the two rooms of the teahouse.

In source text, a vivid picture of the Poor's life has been formed, which paves the way to the description of Hua Laoshuan's mood with both hope and anxiety when buying streamed bread through the situation description. But in translation, the "bluish-white light" is translated to "ghostly light" adding mysterious and strange atmosphere which seeds the character's tragedy in the next context via gloomy mood in translation.

Source text: He looked up around; only saw many odd people in twos and threes, wandering like ghosts on the street. ${ }^{9}$

The version: then he looked around and saw many strange people, in twos and threes, wandering about like lost souls.

In source text, these people are compared as "ghost" indicating that Chinese people in that time are insensitive and own non-consciousness just like ghost. But in translation, it is translated to "lost souls" adding subaudition, that is people's thoughts and souls are lost which forms a strange situation. When readers read here, they will imagine from the "strange people" to the phrase "twos and threes" and finally they will understand when read the phrase "lost soul" which paves the way to the description of people's indifference of revolutionist's death in next context. Thus readers will receive aesthetic feelings during the procedure of thinking.

\section{CONCLUSIONS}

Conclusively, there are three effects of emphasis on literariness in intrinsic approach: (1) traditional translation theory draws much attention to the faithfulness and equivalence of translation or its acceptability and influences in foreign cultures ending in overlook of its literariness. But it is literariness that allows literature being literature; (2) with the growth of cultural consumption, literature gets commercialized reduced into a "product" with certain functions instead of literature itself. For this reason, this paper focuses on the value of literature in an intrinsic way; (3) mass culture is experiencing rapid development and people prefer to secular culture and recreation. In fact, translation activities have lowered the difficulty of contacting literature's original value. On the other hand, if people always talk about translation's faithfulness or its social influences and ignore the inherent problems of literature, "the value of worship will be replaced by the value of show which causes the loss of mysterious aura due to ...overmuch copy procedure and it descends into a consumption symbol." (Xu, 2012, p.135) and that is literature's aura put forward by Benjamin, which means that literature should have mystique, authenticity and the value of worship. Once they disappear, the aesthetic value will fade way as well.

\section{A. Findings}

To be specific, from what has been discussed above, it is clear that in the translation of Medicine, there are "blanks" caused by new imagery from nomination interacting with obscure and implicit context. And during reading the translation, reader may imagine a lot and arouse their emotions or thoughts in the mind. And that experience or the procedure of imagination and thinking is the literariness of Medicine.

Traditionally, people view translation as a static process: some imagery is transmitted in source text through language symbol system which can be translated into target one. In the process of translation, the imagery corresponding to translated text will merge. And people believe that if the source language symbol system and the target one equal basically, thus the imageries inherent in two texts equal as well. The process is as following:

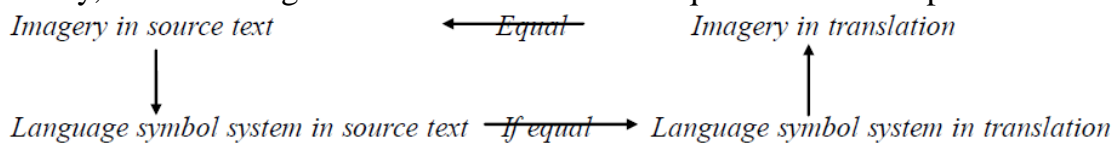

In reality, the imagery in source text and translation cannot be mentioned in the same breath because they are totally different subjects after the dynamical translation.

Nowadays, translation is regarded as a dynamical process. Hardly can translator completely convey imagery of source text into target one by transforming language symbol system purely due to the unavoidable variation. Although the imagery archetype of translation is from source text, it will be generated automatically and differently via language

\footnotetext{
${ }^{8}$ This excerpt is translated by author. The Chinese one is: “华老栓忽然坐起身, 燃着火柴, 点上遍身油淢的灯盛, 茶馆里的两间屋子里, 便弥 漫了青白的光。”

${ }^{9}$ This excerpt is translated by author. The Chinese one is: “仰起头两面一望, 只见许多古怪的人, 三三两两, 鬼似的在那里徘徊。”
} 
symbols involving in both of source text and translation as well as the interaction with each, which implies that language symbol system merely severe as carrier. Therefore, translation becomes a new literature along with its own imagery and literariness. And the process is as following:

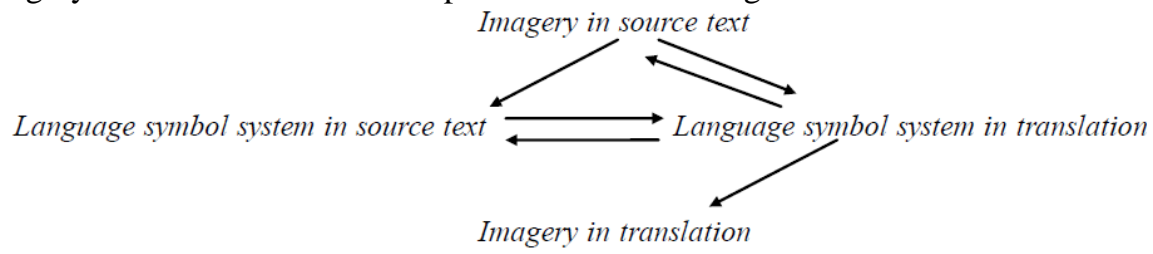

\section{B. Limitation in Methodology and Suggestions}

As a matter of fact, language is included in symbol system, but more and detailed information has not been presented in this paper which may be incomprehensive. Besides, since translation has been studied in comparative literature in this paper, the value of translation has been emphasized with an example of English version Medicine which may have views of literariness overshadowed by the trivial. Thus a more comprehensive and systematic study is needed.

\section{REFERENCES}

[1] Cao Shunqing. (2001). The Course of Comparative Literature. Beijing: Higher Education Press.

[2] Cao Shunqing. (2006). The Research Field of Literary Variation in Comparative Literature. Fudan Journal (Social Science Edition), 1, 80-83.

[3] Cao Shunqing. (2006).Variations Studies in Comparative Literature. The World Literature Criticism, 1, 14-18.

[4] Chen Dun, Sun Jingyao \& Xie Tianzheng. (1997). Comparative Literature. Beijing: Higher Education Press.

[5] Cong Zihang. (2006). Reductionism and Translation Commenting on Reductionist Approach to Translation. Foreign Languages Research, 4, 77-79.

[6] Cui Jie. (2009). View on Arts of Character's Nomination in Lu Xun's Novels. Anhui Literature, 3, 118.

[7] Dang Zhengsheng. (2012). The Comparative Research of the Arts of A Dream in Red Mansions's English Translation, based on the Versions of Hawkes and Yang Hsien-yi. Beijing: Peking University Press.

[8] Fei Xiaoping. (2003). "Translation Studies" and Cultural Studies: Two Interacting Aspects. Journal of Xinjiang University (Philosophy and Social Science Edition), 4, 134-137.

[9] Hou Qishan \& Peng Qi. (2011). Comparing two English Versions of Lu Xun's Medicine. Journal of Shaoxing University (Philosophy and Social Sciences Edition), 1, 31-33.

[10] Ji Dongmei. (2010). The Atmosphere Infiltration in Situation---Gloomy Style in Lu Xun's Novels. Science \& Technology Information, 25, 149.

[11] Liu Miqing. (2005). New Contemporary Translation Theories. Beijing: China Translation and Publishing Corporation.

[12] Lu Xun. (2009). Medicine. In Lu Xun (Eds.), Call to Arms (Yang Hsien-yi and Gladys Yang, Trans.). Nanjing: Yilin Press, $52-$ 69.

[13] Ma Jiesen. (2011). Summary of Studies on Lu Xun's Novels in China. Journal of Inner Mongolia University for Nationalities, $1,1-3$.

[14] Meng Weigen. (2003). On the Translation of Dialectal Words in Lu Xun's Novels. Journal of Shaoxing College of Arts and Sciences, 5, 36-38.

[15] Teng Wei. (2006). The Meeting of Translation Studies and Cultural Studies. Comparative Literature in China, 4, 126-135.

[16] Wellek, René \&Austin Warren. (2010). Theory of Literature (Liu Xiangyu, Xing Peiming, Chen Shengsheng \& Li Zheming, Trans.). Beijing: Culture and Art Publishing House.

[17] Wang Ning. (2009). Comparative Literature and Cultural Turn in Translation Study. Chinese Translators Journal, 5, 19-26.

[18] Wang Wei. (2005). Faithfulness and Manipulation. Foreign Language Education, 5, 79-82.

[19] Wang Yaming \& Wei Li. (2010). Comments About the Yangs' Translation from the Perspective of Barkhudarov's Semiotic Translation Theory__ Taking English Versions of Lu Xun's Novels Medicine and Greeting for Example. Journal of Liaoning Medical University (Social Science Edition), 5,105-108.

[20] Xu Jing. (2012). Introspection on Literary Theory Discourse of Chinese Elegance and Vulgarity. Social Scientist, 3, $133-136$.

[21] Xu Jun. (2002). On the Relationship between Translation and Source Text. Foreign Language Teaching and Research, 1, 1521.

[22] Xu Shuqi. (2003). Analysis on Meanings of Character's Nomination in Lu Xun's Novels. Journal of Inner Mongolia Radio and Television University, 1, 10-11.

[23] Yan Yuezheng. (2010). Guo Shaoyu and Western Literature Ideological Trend, a Case Study on History of Chinses Literary Criticism. Literary Review, 1, 100-105.

[24] Yang Jianding \& Sun Hongren. (2001). Summary of English Versions of Lu Xun's Novels. Luxun Research Monthly, 1, 1-3.

[25] Zeng Jianping \& Zhong Daxiang. (2005). On Translation's Acceptability. Journal of Nanchang University (Social Science), $4,142-146$.

[26] Zhou Moshu. (2012). Aesthetics of Reception and Literary Translation. Literature, 3, 83-85.

[27] Zhou Xiaoyi. (2003). Literariness. Foreign Literature, 5, 51-63.

[28] Zhu Zhirong. (2008). History of Western Literary Theory. Beijing: Peking University Press. 


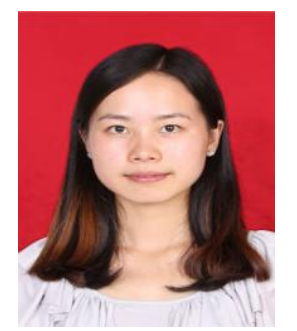

Qing Yang was born in Sichuan, China in 1991. Now she is an undergraduate student majoring in English in Sichuan Agricultural University, China. 